Marquette University

e-Publications@Marquette

Psychology Faculty Research and Publications

Psychology, Department of

4-8-2011

\title{
Catastrophe Models for Cognitive Workload and Fatigue
}

Stephen J. Guastello

Marquette University, stephen.guastello@marquette.edu

Henry Boeh

Marquette University

Curt Shumaker

Marquette University

Michael Schimmels

Marquette University

Accepted version. Theoretical Issues in Ergonomics Science, Vol. 13, No. 5 (2012): 586-602, DOI. (C) 2012 Taylor \& Francis. Used with permission. 


\title{
Catastrophe Models for Cognitive Workload and Fatigue
}

\author{
Stephen J. Guastello \\ Psychology Department, Marquette University \\ Milwaukee, WI \\ Henry Boeh \\ Psychology Department, Marquette University \\ Milwaukee, WI \\ Curt Shumaker \\ Psychology Department, Marquette University \\ Milwaukee, WI \\ Michael Schimmels \\ Psychology Department, Marquette University \\ Milwaukee, WI
}

\begin{abstract}
We reconceptualised several problems concerning the measurement of cognitive workload - fixed versus variable limits on channel capacity, work volume versus time pressure, adaptive strategies, resources demanded by tasks when performed simultaneously, and unclear distinctions between workload and fatigue effects - as two cusp catastrophe models: buckling stress resulting from acute workload, and fatigue resulting from extended engagement. Experimental participants completed a task that was intensive on non-verbal episodic memory and had an automatically speeded component. For buckling stress, the epoch of maximum (speeded) performance was the asymmetry parameter; however, anxiety did not contribute to bifurcation as expected. For fatigue, the bifurcation factor was permission has been granted for this version to appear in e-Publications@Marquette. Taylor \& Francis does not grant permission for this article to be further copied/distributed or hosted elsewhere without the express permission from Taylor \& Francis.
\end{abstract}


NOT THE PUBLISHED VERSION; this is the author's final, peer-reviewed manuscript. The published version may be accessed by following the link in the citation at the bottom of the page.

the total work accomplished, and arithmetic, a compensatory ability, was the asymmetry parameter; $R^{2}$ for the cusp models outperformed the linear comparison models in both cases. A research programme is outlined that revolves around the two models with different types of task and resource configurations.

Keywords: cognitive workload; fatigue; cusp; catastrophe; episodic memory

\section{Introduction}

The trend towards increased automation has had the effect of increasing mental workload on the operators, particularly if they are expected to operate many automated systems simultaneously (Eberts and Salvendy 1986). Although 'downsizing' is nothing new, the workload problem is likely to have increased in the recent wave of unemployment where some workers are terminated, leaving the remaining workers to cover the same amount of work; the impact of downsizing on work flow dynamics can be highly variable (Guastello and Johnson 1999).

This study addresses the theoretical bases for understanding and measuring cognitive workload and fatigue. Several problems in the literature remain unresolved and offer some opportunities for development. (1) The measurement of workload is relative to the task situation and not particularly generalisable. (2) It remains ambiguous as to whether the upper limits to channel capacity are better explained by fixed or variable limits. (3) When two or more tasks are performed simultaneously, their impact on channel utilisation is not additive. (4) Adaptation, coping or resilience are possible explanations for variable upper limits. (5) There is some confusion with regard to where the effects of work overload end and the effects of fatigue begin.

The potential solution to the cluster of concerns takes the form of two catastrophe models for the effect of work load on performance and the effects of fatigue. They have similar structures, but derive from different underlying dynamics. Contributing variables play different roles in each model. The experiment that follows tests the hypotheses that the models are viable explanations for distinct but 
related problems in workload and fatigue, and opens up an avenue of new research possibilities.

\section{Problems in cognitive workload and fatigue}

The early research offered simplistic statements such as 'human mental capacity is 10 bits per second,' but later work indicated that processing capacity was highly relative to the task (Kantowitz 1985). Unfortunately, that relativism created problems with workload measurements that were incompatible across types of tasks (Neerincx and Griffioen 1996); this is a problem that still persists (Lin and Cai 2009, Morineau et al. 2009). For instance, cognitive workload for air traffic controllers is directly related to the number of planes taking off or landing in a given time period (Chatterji and Sridhar 2001, Loft et al. 2007); such conclusions are not particularly generalisable to situations that do not involve airplanes, except perhaps through some speculative abstractions.

\subsection{Fixed versus variable upper limits}

Experiments support both the notion of a fixed upper limit in cognitive capacity and a variable upper limit in cognitive capacity (Kantowitz 1985). In the fixed capacity explanation, tasks require channel capacity in different amounts. When two or more tasks do not consume the full capacity, no impairments in performance times or error rates are likely. When the total demand of simultaneous tasks reaches a critical point, however, errors increase or production drops. The operator's mind, meanwhile, operates in a manner similar to a time-sharing computer where mental resources are allocated to one task then to another.

The variable upper limit explanation does not posit a fixed point, but rather the operator's capacity can expand as a result of excess demand or increased motivation; however, a limit would be reached eventually. The rules by which the upper limit could be more flexible have not been fully ascertained, but some explanations exist for why some task situations would produce a variable upper limit or why the demands of simultaneous tasks might not add up in a simple fashion to a fixed upper limit. Explanations include the internal structure of the 
task, nature of the demands on task resources, overall arousal level and coping strategies.

The internal structures of the tasks affect the results: For a visual search task, response time increases with the number of stimuli that need to be processed, but the increment in response time depends on whether the search is exhaustive or first-terminating (Townsend and Wegner 2004). When multiple tasks are in operation, tasks performed in parallel are not completely independent, which is tacitly assumed in the fixed upper limit explanations; cross-talk between channels is possible. A bottleneck (Figure 1) could slow the system as the tasks wait for movement into phases that need to be performed serially, or the information flow from one channel facilitates completion of a task coming in from another channel.

Figure 1. Two parallel tasks reaching a bottleneck position.

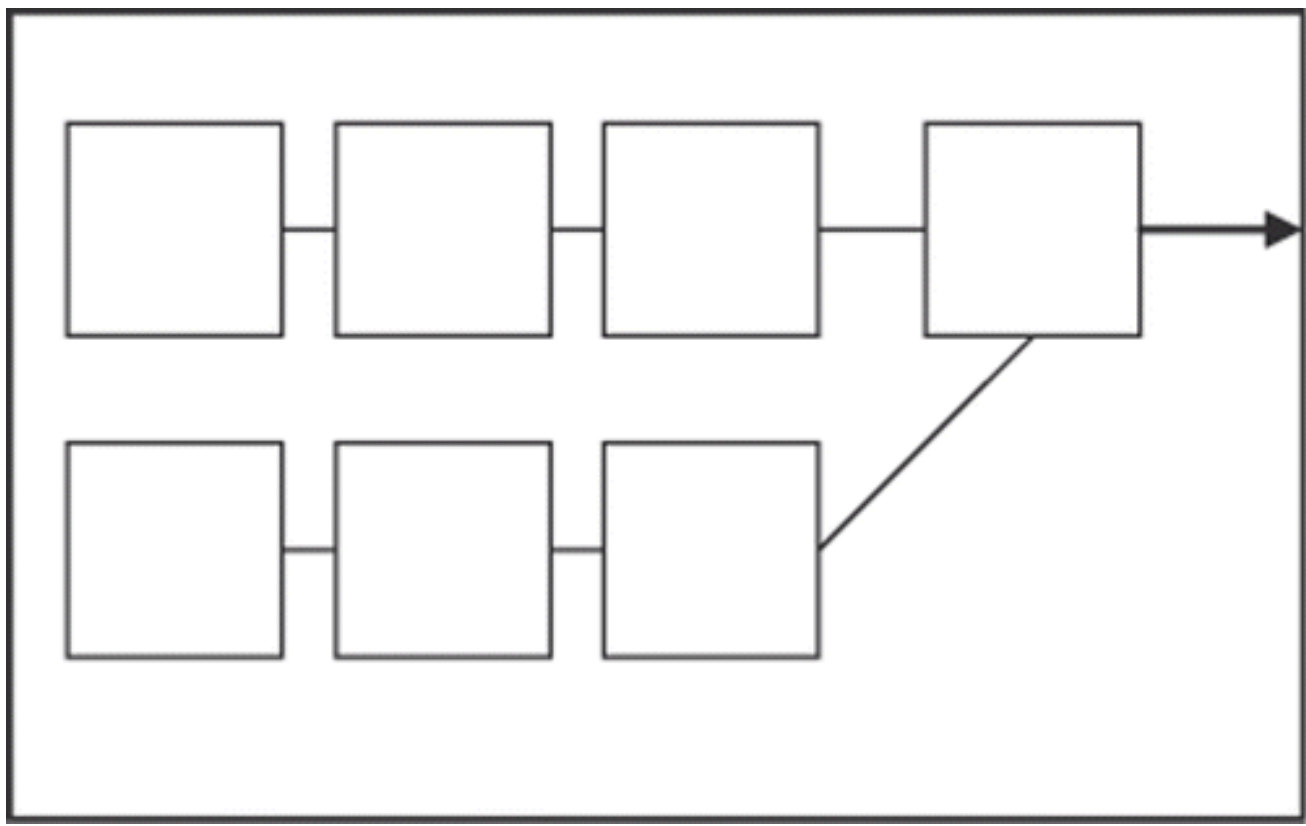

The mental resources demanded by combinations of tasks could produce results that are not simply additive. In a recent review, Wickens (2008) observed that if two or more tasks demanded the same resources, such as visual attention, the two tasks could readily conflict. Whereas, if the two tasks involved different resources, perhaps a visual and an auditory combination, the drain on operator capacity could be substantially less or non-existent.

Theoretical Issues in Ergonomic Science, Vol 13, No. 5 (2012): pg. 586-602. DOI. This article is (C) Taylor \& Francis and permission has been granted for this version to appear in e-Publications@Marquette. Taylor \& Francis does not grant permission for this article to be further copied/distributed or hosted elsewhere without the express permission from Taylor \& Francis. 
The classic inverted- $U$ function that relates arousal to performance also appears to be a mitigating phenomenon that disturbs the simple relationship between task demands and performance. Lin and Cai (2009) observed that greater task demands increase arousal, and thus could, for some ranges of demand, result in improved task performance overall.

\subsection{Sources of elasticity}

Another important issue here is the nature of elasticity in the cognitive context. Several types of coping strategies have been suggested in the literature. One involves organising mental operations involved in the work in serial or parallel configurations that optimise the results, particularly when multiple tasks are being executed simultaneously. Another is to focus attention away from distractions, secondary tasks and task-irrelevant social cues (Hancock and Warm 1989). Coping strategies benefit from both the ability to allocate mental resources and the ability to control properties of the task or the task environment (Hockey 1997). The role of motivation is observed when the operators gauge their efforts with respect to internalised goals and performance standards. Some working conditions are more enabling in this regard (Hockey 1997, Harris et al. 2005).

Anxiety or trait neuroticism also plays an interesting role. Studies from different origins indicate that anxiety can have both positive and negative impacts on performance under stressful conditions (Guastello 2003, 2006, Matthews and Campbell 2009, EinDor et al. 2010, Guastello and Lynn 2010). The negative impact of stress is perhaps more familiar: it leads to breaking concentration, response, delays, distortions of judgment and errors generally. The positive impact is that it is sometimes associated with greater vigilance and attentiveness to small cues in work that could have a large impact. By having both positive and negative roles, anxiety functions as a bifurcation variable, as do other aspects of resilience or coping behaviour (Hancock and Warm 1989, Sheridan 2008, Pincus and Metten 2010, Guastello 2011).

Theoretical Issues in Ergonomic Science, Vol 13, No. 5 (2012): pg. 586-602. DOI. This article is (C) Taylor \& Francis and permission has been granted for this version to appear in e-Publications@Marquette. Taylor \& Francis does not grant permission for this article to be further copied/distributed or hosted elsewhere without the express permission from Taylor \& Francis. 
NOT THE PUBLISHED VERSION; this is the author's final, peer-reviewed manuscript. The published version may be accessed by following the link in the citation at the bottom of the page.

\subsection{Effects of workload versus fatigue}

Progress in the study of cognitive workload and fatigue has been hampered by confounded definitions of the two phenomena (Hancock and Desmond 2001). Thus, we adopt behavioural definitions here along with physiological notions of workload and fatigue, which are more clearly separated, with the intention of carrying the distinction through to cognitive workload and fatigue issues.

Stress is any demand on the organism (Selye 1976); demand can be uncomfortably low or high, but practical preoccupation is on the effect of high stress levels. Stress can emanate from physical sources, such as heat or cold, social conflicts, or workload or work speed demands. Workload and work speed often go together. The classic finding is that the cross-product of speed and load is linearly related to the number of errors produced (Conrad 1951). Conrad's clockwatching study only involved one type of task, however, and research has resumed on the development of speed-load models that would pertain to broader ranges of tasks in combination that could vary with regard to load intensity or time-pressure (Hendy et al. 1997).

Fatigue is often cited as a stress reaction, but it is also considered as a phenomenon in its own right, and defined as the loss of work capacity over time (Guastello and McGee 1987) for both cognitive and physical labour (Guastello 1995). Depletion of work capacity is typically assessed by a work curve that plots performance over time; there is a sharp drop in performance when fatigue sets in that is also coupled with a higher level of performance variability over time. However, not everyone experiences a decline as result of the same expenditures. Some show an increase in physical strength akin to 'just getting warmed up,' while others show stably high or lower performance levels for the duration of the work period. Thus, a cubic polynomial function was first introduced by Ioteyko (1920) to account for the classic and more common work curve plus all the other variations.

Physical fatigue is partially the result of how much work was accomplished by the individual during a fixed period of time. Physical fatigue is also attenuated by the compensatory abilities. For instance, if the task demands arm strength primarily, most people would show a decrease in arm strength compared to pre-work levels, but the effect

Theoretical Issues in Ergonomic Science, Vol 13, No. 5 (2012): pg. 586-602. DOI. This article is (C) Taylor \& Francis and permission has been granted for this version to appear in e-Publications@Marquette. Taylor \& Francis does not grant permission for this article to be further copied/distributed or hosted elsewhere without the express permission from Taylor \& Francis. 
would be less severe if initial leg strength was also high. Thus, Guastello and McGee (1987) combined the cubic function, total amount of work accomplished and compensatory abilities into a cusp catastrophe model for fatigue that serves as the basis for one of the cognitive models studied here.

If one were to conceptualise workload or fatigue effects as a time series problem, there is some sense that an operator's work capacity would be related to the load that the operator experienced in the recent past (Cox-Fuenzalida 2007). When this effect is viewed in isolation, it is not clear whether it is an illustration of a coping mechanism in action, and thus part of a buckling phenomenon or an exercise effect associated with fatigue and work capacity. Catastrophe models, however, do use prior performance as a part of the prediction of future performance, so it should be possible to examine this type of effect through cusp catastrophe analysis.

\section{Catastrophe models for cognitive workload and fatigue}

This research programme builds on mathematical models developed earlier, mostly in the context of physical work, to build a workable theory of cognitive load and work performance and for fatigue in cognitively demanding work. The two models have the same mathematical structure, but the roles of specific variables are different.

\subsection{Buckling model for workload}

The cognitive workload model invokes the notion of stiff versus flexible systems from material science. A piece of material that is subjected to sufficient amounts of stress will show a certain amount of deformity or strain. Rigid materials will break, while flexible materials will rebound. The amount of deformity induced by stress is the stressstrain ratio. The connection between material strain and the cusp catastrophe was made some time ago with regard to physical materials (Zeeman 1977) and human systems (Guastello 1985). Figure 2 shows a beam of relatively stiff material that is pin-jointed at both ends. A weight is placed on the beam. If the material is rigid, and the weight is not supercritical, there will be little visible buckling. When

Theoretical Issues in Ergonomic Science, Vol 13, No. 5 (2012): pg. 586-602. DOI. This article is (C) Taylor \& Francis and permission has been granted for this version to appear in e-Publications@Marquette. Taylor \& Francis does not grant permission for this article to be further copied/distributed or hosted elsewhere without the express permission from Taylor \& Francis. 
the vertical weight becomes too large, the beam will snap. On the other hand, if the material has a high degree of elasticity, the weight will cause the beam to waffle, more weight could cause it to waffle more, but the beam would not snap.

Figure 2. Buckling of an elastic or rigid beam when weight is applied vertically.
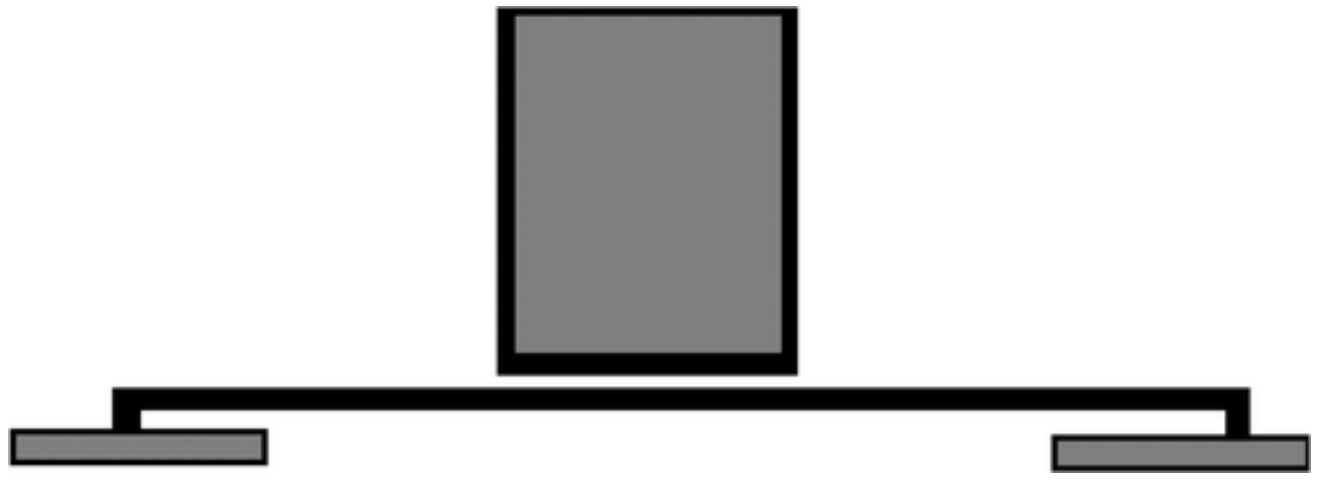

The beam-buckling relationship is characterised as a cusp catastrophe model (Figure 3)

$$
\frac{\mathrm{d} y}{\mathrm{~d} t}=\mathrm{Y} 3-\mathrm{by}-\tilde{a}
$$

Performance or response time would be the dependent variable, $y$, which has two stable states of high and low performance, a separation between the two states, and two control parameters, $b$ and $a$, that govern the change between states. The amount of vertical weight is the asymmetry (a) parameter. The modulus of elasticity of the material is the bifurcation factor $(b)$, with low elasticity located at the high end of the bifurcation axis. Great elasticity or resilience, is located at the low end of the bifurcation axis. Coping strategies, resilience and anxiety levels would correspond to the bifurcation variable. 
Figure 3. Two stable states of work performance as a function of elasticity (resilience) and workload.

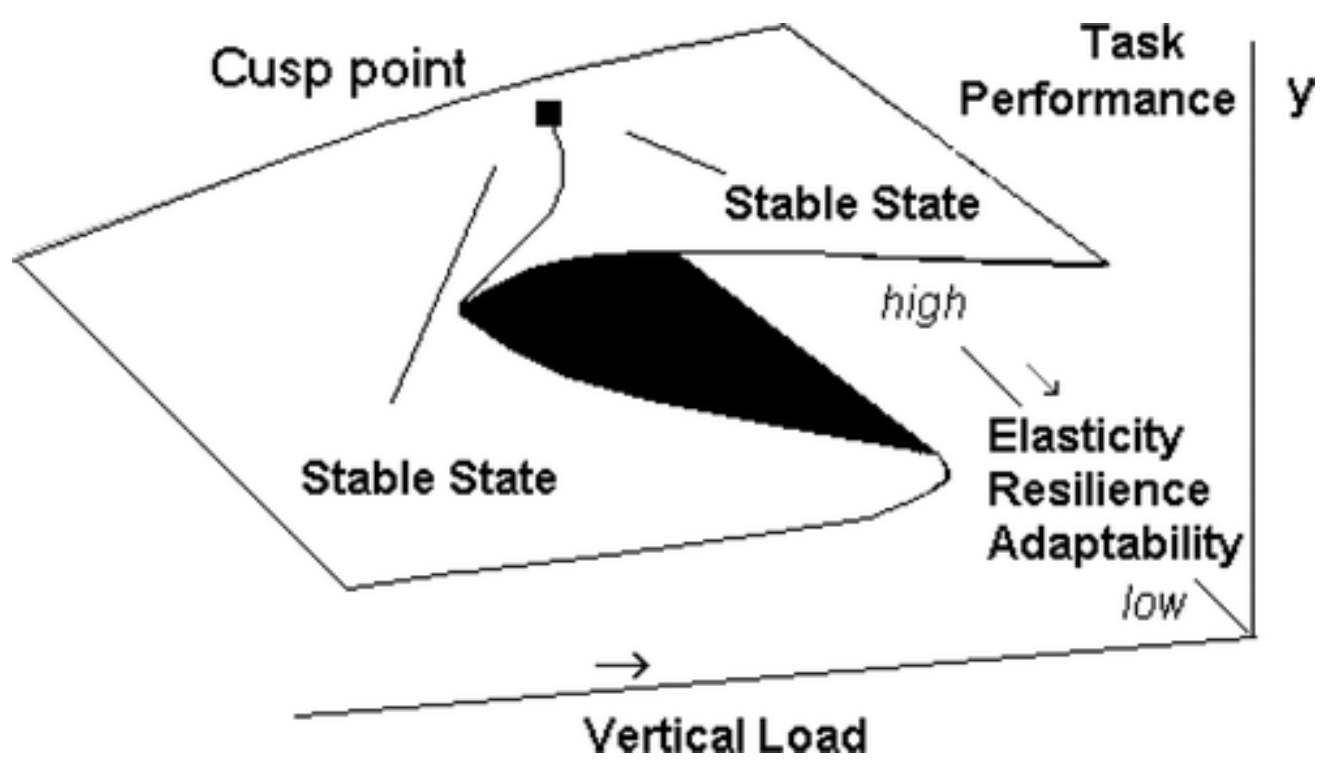

Workload in this context is defined as a static quantity of demand placed on the operator. The operator's performance level is thought to fluctuate as a result of increased load. The fluctuations are small and gradual for highly elastic conditions and either non-existent or dramatic in non-elastic conditions. In the original example (Guastello 1985), labourers pushed a wheelbarrow through an obstacle course, carrying a load of $45.5 \mathrm{~kg}$ (100 lbs), $91 \mathrm{~kg}$ (200 lbs) or $136.4 \mathrm{~kg}$ (300 lbs) of sand. The participants in the study did not have much difficulty moving the $45.5 \mathrm{~kg}$ load through the obstacle course in about $1 \mathrm{~min}$. When the load increased to $91 \mathrm{~kg}$, the performance trajectories divided between those who could still move through the course in less than a minute and those that required much longer time. The split between the fast and slow performers increased when the load was increased to $136.4 \mathrm{~kg}$. Several variables that were also measured in the study, such as height, were found to contribute to the bifurcation parameter, and thus constituted elasticity in physical response for the task. No cognitive studies with the buckling model have been reported until now. 
NOT THE PUBLISHED VERSION; this is the author's final, peer-reviewed manuscript. The published version may be accessed by following the link in the citation at the bottom of the page.

\subsection{Fatigue}

The fatigue model has the same structure as defined in Equation (1) and Figure 4, but the variables that contribute to the control parameters are different. Work capacity is the dependent measure that displays two stable states. Capacity and performance at a single point in time are not always easy to distinguish, but in principle it is the capacity that is subject to dramatic or small change over time. The total quantity of work already done would be the main contributor of the bifurcation parameter; if the individual did not accomplish much in a fixed amount of time, there would be little fatigue in the sense of work capacity.

Figure 4. Cusp model for fatigue.

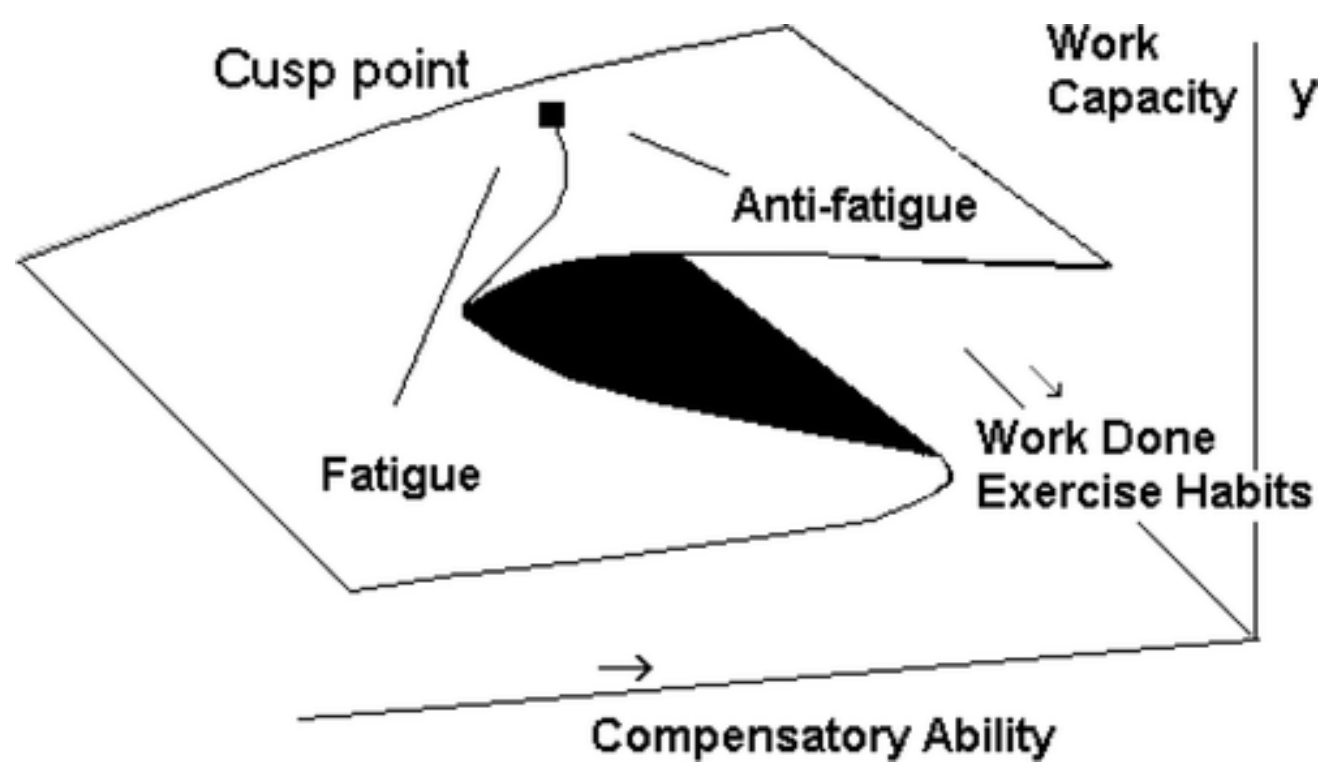

The asymmetry parameter would be a compensatory strength measure. For instance, in the original example, labourers displayed differences in arm strength as a result of about $2 \mathrm{~h}$ worth of standard mill labour tasks, which were primarily demanding on arm strength. They were measured on isometric arm strength and leg strength using a dynamometer before and after the work session. Leg strength showed little change after the work session, which was not surprising,

Theoretical Issues in Ergonomic Science, Vol 13, No. 5 (2012): pg. 586-602. DOI. This article is (C) Taylor \& Francis and permission has been granted for this version to appear in e-Publications@Marquette. Taylor \& Francis does not grant permission for this article to be further copied/distributed or hosted elsewhere without the express permission from Taylor \& Francis 
but it did act as a compensation factor for arm strength; those with greater leg strength experienced less fatigue in their arms, all other things (such as total work accomplished) being equal.

A similar fatigue dynamic is thought to be operating in mental tasks, as the same system of work curves as reported in the early twentieth century literature (reviewed in Guastello and McGee 1987). Guastello (1995) analysed a published data set from a cognitive fatigue study by Ash (1914), and found the cusp model to be a good fit for a data. The data set did not provide many options for studying control variables, so the compensatory abilities were not identified. In new experiments, however, one could investigate, for example, whether verbal fluency or fluency in arithmetic compensated for a high memory demand.

Another problem with fatigue studies is that prolonged work periods can induce a practice effect while the work period is setting the stage for fatigue. In the Ash experiment, the participants engaged in four experimental sessions. The likelihood of a discontinuous downward shift in performance declined over the four sessions. The session number thus functioned as an asymmetry variable in the cusp model.

\subsection{Degrees of freedom}

Catastrophe models, phase shifts and self-organising dynamics are all closely related (Gilmore 1981, Haken 1988, Guastello 2005). Self-organising dynamics are typically the result of interactions, information flows or communications among the subsystems. The concept of degrees of freedom, which was first introduced by Bernstein (1967) and Turvey (1990) in conjunction with physical movements, goes a long way towards explaining why the cusp dynamics occur and to some extent why fixed and variable upper limits to cognitive channel capacity are both viable.

In any particular complex movement, each limb of the body is capable of moving in a limited number of ways, and the movements made by one limb restrict or facilitate movement by other limbs. For this reason, we do not walk by stepping both feet forward simultaneously, for instance. The notion of internally connected nodes of movement is substantially more efficient, and simpler, than

Theoretical Issues in Ergonomic Science, Vol 13, No. 5 (2012): pg. 586-602. DOI. This article is (C) Taylor \& Francis and permission has been granted for this version to appear in e-Publications@Marquette. Taylor \& Francis does not grant permission for this article to be further copied/distributed or hosted elsewhere without the express permission from Taylor \& Francis. 
assuming that all elements of movement are controlled by a central executive function. When a movement is in its earliest stages of being learned for the first time, several optional combinations are explored by the individual; but once learning sets in, the movement combinations gravitate towards the conservation of degrees of freedom, which is in essence a path of least resistance (Hong 2010). The gravitation is actually a self-organisation dynamic. Some variability in the movement still persists, however, which facilitates new affordances or variations in stimuli, from the environment or the definition of new goals originated by the individual (Abbott et al. 2005, Hristovski et al. 2006, Mayer-Kress et al. 2009). Sufficiently large changes in goals or demands produce a phase shift in the motor movements, which are observed as discontinuous changes in the sense of catastrophe models.

Cognitive behaviours are thought to operate on more or less the same principle with regard to the early and later stages of schematic development, the role of executive functions and the principle of conserving degrees of freedom (Hollis et al. 2009). Furthermore, cognition is tied to action in many cases, so that the entire array of relevant degrees of freedom now pertain to the perception-action sequences (Renaud et al. 2009). The current thinking from a nonlinear dynamics perspective was strongly influenced by Gibson's (1979) ecological perspective. More generically, degrees of freedom are the number of component parts, such as muscles or neural networks that could function differently to produce the final performance result (Marken 1991, Rosenbaum et al. 1991). When the self-organised pattern shifts to a different pattern due to a change in the performance demand, the catastrophic shift in performance is produced.

In the case of work overload resulting from a fixed upper limit of channel capacity, the discontinuity in performance would be the simple result of hitting a barrier. As such there would be little room for the kind of elasticity associated with bifurcation effects or the phenomena of variable upper limits. If variable upper limits were operating, however, the principle of conserving degrees of freedom would have a few implications; in the case of adding tasks or other demands to existing tasks, a change in one cognitive-behavioural motion would impact on the other motions in the system or sequence. If it were 
possible to conserve degrees of freedom further, a phase shift in the cognition-action sequence would result in the observed catastrophic effect. The bifurcation variables suggested in Figure 3 would distinguish features of the individual or system that would or not permit the appropriate adaptation. For example, increased demand for visual search could result in a shift from an exhaustive search to an optimised first-terminating strategy (Townsend and Wegner 2004).

In the case of fatigue, Hong ( $\underline{2010})$ observed that the increase in performance variability during the low-production period suggests an internal search for a possible reconfiguration of degrees of freedom. There are two plausible scenarios, however, neither of which is thought to be universal at the present state of science. According to the redistribution principle, the individual is searching for a lowerentropy means of accomplishing the same task or goal. If a loss of total entropy was occurring, however, the individual would not only be trying to regroup internal resources, but also reducing responsiveness to the total complexity of task situations and demands, gravitating towards what amounts to the easier task options, situations or to simpler tasks.

\subsection{Hypotheses}

So far we have delineated task differences that impact on work load and performance outcomes. They involve serial, parallel and hybrid configurations (Kantowitz 1985), exhaustive versus firstterminating searches (Townsend and Wegner 2004) and analogous processes, differences in intensity due to task complexity versus timesensitivity (Hendy et al. 1997), and tasks that compete for resource allocation (Wickens 2008) versus those that benefit from compensatory abilities (Guastello and McGee 1987). The experiment that follows was framed as a basic problem involving one demanding task that had the potential for utilising compensatory resources in addition to the central mental demand. The task demanded non-verbal episodic memory that also had some resemblance to digit-span memory. The task design contained a built-in feature where the load and time pressure increased according to some regular rules.

The first central objective of the experimental design was to illustrate (1) the cusp catastrophe dynamics of workload, and (2) the 
impact of anxiety as a possible elasticity or bifurcation variable. The second central objective was to illustrate (3) the cusp catastrophe model for fatigue, (4) the role of total work accomplished as a bifurcation variable and (5) compensatory abilities as the asymmetry variables.

\section{Method}

\subsection{Participants}

Subjects were 181 undergraduates who were enrolled in psychology courses. The first 108 participated in the development of two of the measurements that were used in the main experiment (calibration sample). The measurements were parallel forms of an arithmetic test and a spelling test that were administered at the beginning and end of the experimental session. The other 73 undergraduates participated in the main experiment.

\subsection{Experimental procedure}

Half of the participants in the experiment performed the following sequence of activities: (1) 2 min for learning the experimental task, (2) Form A of the spelling test, (3) Form A of the arithmetic test, (4) the anxiety test, (5) the central experimental task, (6) Form B of the spelling test and (7) Form B of the arithmetic test. The other half of the participants will perform the same sequence of activities except that the order of the arithmetic and spelling tests will be reversed. Within each half, participants were further counterbalanced so that half (one quarter of the total) received Form $A$ of the arithmetic and spelling before Form B, and the other half received Form $B$ before form $A$. The arithmetic and spelling tests were timed (speeded) to last 5 min each. The central experimental task was timed to last $20 \mathrm{~min}$. The total participation time was $1 \mathrm{~h}$ in one session.

The experimental task was computer-based version of the game MySimon (Neave 2009). The game stimuli consist of a picture of a four-colour geometric object, in which one of the coloured areas lights up when a tone is played. The game begins with the presentation of one tone and one coloured light. The participant clicks the same

Theoretical Issues in Ergonomic Science, Vol 13, No. 5 (2012): pg. 586-602. DOI. This article is (C) Taylor \& Francis and permission has been granted for this version to appear in e-Publications@Marquette. Taylor \& Francis does not grant permission for this article to be further copied/distributed or hosted elsewhere without the express permission from Taylor \& Francis. 
coloured light with the mouse. The game continues with a sequence of two lights and tones, which the participant repeats. If the participant makes the correct response, the game continues with progressively longer sequences of lights and tones. The presentation time for the lights and times is progressively faster as well. A counter on the screen gives the participant feedback as to how many points have been accumulated in an unbroken sequence of correct responses.

If the participant made an error, the system reverted to sequences of one tone and light and continued to expand the sequence again. Performance points for the experimental data were recorded as the number of correct responses within a fixed period of time. Recordings were made using tracking software ( $\mathrm{NCH}$ Software 2009) installed on the computer. The video record that it produces consisted only of movements of the cursor on the computer screen and did not capture any visual or audio images of the participants themselves.

\subsection{Measurements}

The measurements used in the study were the two parallel measures of spelling ability, the two parallel measures of arithmetic ability, manifest anxiety and several measurements taken from the MySimon game. The MySimon task places a high demand on short term memory (or working memory). The task itself is similar to the digit-span memory test that appears on some intelligence tests. Performance on the MySimon task also requires focused attention. If the participant's attention lapses on a long sequence, which can happen when fatigue sets in (Bills 1931), the participant would not be able to answer correctly.

Total work was the total number of points scored on MySimon during the 20-min session. Peak score was the total number of points scored during the participant's best 1-min interval. Maximum score was the largest run of points attained by the participant, which often spanned 1-min intervals. Peak score and maximum score were tested interchangeably as measures of work load. For the fatigue analyses, the total number of points on MySimon from the first 3 min of work was compared with the total number of points on the game from the last 3 min of work.

Theoretical Issues in Ergonomic Science, Vol 13, No. 5 (2012): pg. 586-602. DOI. This article is (C) Taylor \& Francis and permission has been granted for this version to appear in e-Publications@Marquette. Taylor \& Francis does not grant permission for this article to be further copied/distributed or hosted elsewhere without the express permission from Taylor \& Francis. 
The arithmetic tests were built from a pool of 50 items that involved addition, subtraction, multiplication and division. Items were randomly assigned to the two forms. Data from the calibration sample indicated that five items on Form A contained no variance and were thus dropped; the resulting $M, S D$ and alpha reliability were 12.71 , 2.57 and 0.67 , respectively. Six items on Form B contained no variance and were thus dropped $(M=12.93, \mathrm{SD}=2.22, a=0.61)$. Because the means and standard deviations were so close, no further adjustments were made to either form, and they were adopted as parallel. The correlation between the two forms, based on the calibration sample, was 0.37 .

The spelling tests were built from a pool of 100 commonly misspelled words that were placed in a sentence. Not all sentences contained misspelled words. The participant was required to find the misspelled word and write the correct spelling on the answer line. If there was no misspelled word, the line should be left blank. The final Form A contained 49 items $(M=31.03, \mathrm{SD}=7.25, a=0.86)$. The final Form B contained 48 items $(M=30.19, \mathrm{SD}=7.52, a=0.89)$. The difference in means indicated that the forms would be reasonably parallel if a constant of 1 was added to Form B. The correlation between the two forms, based on the calibration sample, was 0.67.

The anxiety test was a variation of Taylor Manifest Anxiety symptoms that was used in earlier research on stress and occupational accidents (Guastello 2003). It consisted of 19 statements such as, 'I have nightmares about my job or classes.' The participant responded by checking 'Agree' ( 2 points), '?' (1 point) or 'Disagree' ( 0 points). Some items were reverse scored. Data from the calibration sample indicated that all items should be retained $(M=12.84, S D=7.10$, $a=0.75)$.

\subsection{Analysis}

The first analysis was a standard analysis of variance to determine whether there were any changes in the scores on the parallel forms that were attributed to administering arithmetic before spelling or vice versa.

The cusp analyses were polynomial regression analogues of Equation (2)

Theoretical Issues in Ergonomic Science, Vol 13, No. 5 (2012): pg. 586-602. DOI. This article is (C) Taylor \& Francis and permission has been granted for this version to appear in e-Publications@Marquette. Taylor \& Francis does not grant permission for this article to be further copied/distributed or hosted elsewhere without the express permission from Taylor \& Francis. 


$$
\Delta \mathrm{z}=\beta_{0}+\beta_{1} z_{1}^{3}+\beta_{2} z_{1}^{2}+\beta_{3} b z_{1}+\beta_{4} a
$$

where $z$ was the dependent measure observed at two points in time, $b$ the bifurcation variable, $a$ the asymmetry variable, and all variables were transformed by location and scale before entering into the regression model (Guastello 1995, 2002, 2011), and are thus designated as $z$ instead of $y$. Two or more variables could be entered as $b$ or $a$, and would have additional regression weights associated with them. In the event that statistical significance was not obtained for all the important terms in the model, the quadratic term would be dropped because it was the least central to the cusp structure.

The term $R^{2}$ for the cusp model was compared with $R^{2}$ for two linear comparison models

$$
\begin{gathered}
\Delta y=\beta_{0}+\beta_{1} b+\beta_{2} a, \\
y 2=\beta_{0}+\beta_{1} y_{1}+\beta_{2} b+\beta_{3} a .
\end{gathered}
$$

The linear models involve the same variables that are used as cusp control variables but without the nonlinear structures. Equation ( $\underline{3}$ ) states the relationship as a prediction of change in the dependent measure. Equation ( $\underline{4})$ describes the subsequent performance as a function of prior performance and the research variables. Ideally the $R$ ${ }^{2}$ for the cusp models should exceed the $R^{2}$ for their linear counterparts.

\section{Results}

\subsection{Test order effects}

Irregularities in participant scheduling resulted in 41 people doing the spelling test before arithmetic and 32 vice versa. The withinsubjects effect for spelling showed a significant mean difference between pre-test $(M=27.89, \mathrm{SD}=8.40)$ and post-test $(M=31.01$, $\mathrm{SD}=7.51)$ scores $\left(F_{1,69}=19.07, p<0.001\right)$. There was no significant 
between-subjects effect for test order $\left(F_{1,69}=0.74\right)$ or the test order by pre-post interaction $\left(F_{1,69}=0.09\right)$. However, the within-subjects effect for arithmetic did not show a significant mean difference between pre-test $(M=12.45, S D=2.60)$ and post-test $(M=12.64$, $\mathrm{SD}=2.25)$ scores $\left(F_{1,69}=0.46\right)$. Nor was there any effect for test order $\left(F_{1,69}=0.07\right)$ or the test order by pre-post interaction. It was thus possible to conclude that the experimental session had an antifatiguing effect on spelling performance but not arithmetic, and that the change in test scores were not attributable to the order in which the tests were given.

Bivariate correlations among the principal research variables appear in Table 1. As expected, measurements of one construct were more closely correlated with each other than they were with measurements of other constructs. One interesting detail was that there was a modest correlation between pre-tests of arithmetic and spelling that dissolved after exposure to the experimental treatment. Another was that there was a modest correlation between peak score on MySimon with anxiety, but the connection did not carry over to total work or maximum score.

Table 1. Bivariate correlations among research variables.

\begin{tabular}{|c|c|c|c|c|c|c|c|}
\hline Variables & 2 & 3 & 4 & 5 & 6 & 7 & 8 \\
\hline 1. Total work & $-0.77 * *$ & $0.73^{* *}$ & -0.02 & -0.04 & -0.08 & -0.13 & 0.17 \\
\hline 2. Maximum score & & $-0.49 * *$ & 0.10 & 0.05 & 0.15 & 0.14 & -0.09 \\
\hline 3. Peak score & & & -0.14 & -0.22 & -0.07 & -0.12 & $0.31 *$ \\
\hline 4. Arithmetic pre & & & & $0.48 * *$ & $0.25 *$ & $0.24 *$ & -0.10 \\
\hline 5. Arithmetic post & & & & & 0.10 & 0.17 & -0.10 \\
\hline 6. Spelling pre & & & & & & $0.72 * *$ & -0.13 \\
\hline 7. Spelling post & & & & & & & -0.06 \\
\hline 8. Anxiety & & & & & & & \\
\hline
\end{tabular}

Note: *p50.05, two-tailed; **p50.01, two-tailed.

\subsection{Buckling model}

Results for the cusp model for buckling stress and work load appear in Table 2. The overall $R^{2}$ was 0.44 (adj. $R^{2}=0.41, F$ $4,68=13.50, p<0.001)$ and notably larger than $R^{2}$ for either the linear difference $\left(0.09\right.$, adj. $R^{2}=0.05, F_{3,69}=2.15$, ns) or linear pre-post models $\left(0.32\right.$, adj. $\left.R^{2}=0.29, F_{4,68}=8.16, p<0.001\right)$. The maximum score on the game was an effective asymmetry variable characterising

Theoretical Issues in Ergonomic Science, Vol 13, No. 5 (2012): pg. 586-602. DOI. This article is (C) Taylor \& Francis and permission has been granted for this version to appear in e-Publications@Marquette. Taylor \& Francis does not grant permission for this article to be further copied/distributed or hosted elsewhere without the express permission from Taylor \& Francis. 
vertical load. Anxiety was not successful as a bifurcation variable characterising elasticity.

Table 2. Cusp and linear models for buckling stress and cognitive workload.

\begin{tabular}{lrc}
\hline Variable & $\beta$ & $t$ \\
\hline Cusp model $\left(R^{2}=0.44\right)$ & & \\
$z_{1}^{3}$ & -0.76 & $-6.78^{* *}$ \\
Anxiety $z_{1}$ & 0.05 & 0.51 \\
Maximum score & -0.44 & $-4.09^{* *}$ \\
$\quad$ Peak score & 0.08 & 0.68 \\
Linear difference model $\left(R^{2}=0.09\right)$ & & \\
$\quad$ Anxiety & 0.15 & 1.21 \\
Maximum score & -0.29 & $-2.16^{*}$ \\
Peak score & -0.28 & $-2.03^{*}$ \\
Linear pre-post $\left(R^{2}=0.32\right)$ & & \\
Anxiety & 0.08 & 0.71 \\
Maximum score & -0.52 & $-4.37^{* *}$ \\
Peak score & 0.06 & 0.44 \\
$y_{1}$ & 0.13 & 0.10 \\
\hline
\end{tabular}

Note: *p50.05; **p50.001.

The linear models showed that maximum score, which is a selfinduced level of stress, was negatively associated with performance in the final $3 \mathrm{~min}$. In other words, the higher the load mid-stream, the lower the final performance. The linear pre-post model did not show a significant semipartial correlation between performance in the first $3 \mathrm{~min}$ to performance in the last $3 \mathrm{~min}$, although the bivariate correlation between the two performance measures was 0.29.

\subsection{Fatigue}

Results for the cusp model for fatigue on MySimon appear in Table 3. The overall $R^{2}$ was 0.55 (adj. $R^{2}=0.53, F_{4,68}=21.02$, $p<0.001$ ) and notably larger than $R^{2}$ for either the linear difference (0.05, adj. $\left.R^{2}=0.01, F_{3,69}=1.12, \mathrm{~ns}\right)$ or linear pre-post models (0.50, adj. $\left.R^{2}=0.47, F_{4,68}=16.71, p<0.001\right)$. Significant weights were obtained for all parts of the cusp model. Total work contributed to the bifurcation parameter as expected. Arithmetic and the maximum score both contributed to the asymmetry parameter; high scores on both indices were associated with performance changes in the negative direction.

Theoretical Issues in Ergonomic Science, Vol 13, No. 5 (2012): pg. 586-602. DOI. This article is (C) Taylor \& Francis and permission has been granted for this version to appear in e-Publications@Marquette. Taylor \& Francis does not grant permission for this article to be further copied/distributed or hosted elsewhere without the express permission from Taylor \& Francis. 
NOT THE PUBLISHED VERSION; this is the author's final, peer-reviewed manuscript. The published version may be accessed by following the link in the citation at the bottom of the page.

Table 3. Cusp and linear models for fatigue on MySimon.

\begin{tabular}{lrc}
\hline Variable & $\beta$ & $t$ \\
\hline Cusp model $\left(R^{2}=0.55\right)$ & & \\
$z_{1}^{3}$ & -1.38 & $-5.19^{* * * *}$ \\
Total work* $z_{1}$ & 0.98 & $3.80^{* * * *}$ \\
Maximum score* $z_{1}$ & 0.20 & $-1.88^{*}$ \\
Arithmetic & -0.15 & $-1.82^{*}$ \\
Linear pre-post model $\left(R^{2}=0.50\right)$ & & \\
Arithmetic & -0.19 & $-2.12^{* *}$ \\
Total work & 0.82 & $4.74^{* * * *}$ \\
Maximum score & -0.06 & -0.42 \\
$y_{1}$ & -0.33 & $-2.68^{* * *}$ \\
\hline
\end{tabular}

Note: *p50.10; **p50.05; ***p50.01; and ****p50.001.

Bivariate linear correlations between pre- or post-test arithmetic with either the first or second MySimon measure were not significant. The asymmetry effect was evidently a suppressor or complimentarity effect that emerged when the other parts of the cusp model were present. The maximum score was actually negatively correlated with performance on the first 3 min of the game $(r=-0.46, p<0.01)$ and with the last $3 \min (r=-0.56, p<0.01)$, although not with the change in game performance from beginning to end ( $r=-0.16, \mathrm{~ns})$.

The linear pre-post model showed a significant negative weight for pre-test arithmetic also, a positive weight for total work, and a negative weight for game performance in the first $3 \mathrm{~min}$. Neither the over linear difference model nor any of its weights were significant, so no further report could be made for that model. Attempts to include spelling or peak performance in any of the models did not produce any new significant results.

Cusp models for possible fatigue on spelling and arithmetic were also tested. Total work on MySimon and anxiety were tested as possible bifurcation variables. Arithmetic was tested as a possible compensatory ability for spelling and vice versa. The cusp for spelling produced an $R^{2}=0.26$, but no significant weights were observed. The linear pre-post model was actually better $\left(R^{2}=0.53\right)$, although there was only one significant weight, which was the pre-test spelling

Theoretical Issues in Ergonomic Science, Vol 13, No. 5 (2012): pg. 586-602. DOI. This article is (C) Taylor \& Francis and permission has been granted for this version to appear in e-Publications@Marquette. Taylor \& Francis does not grant permission for this article to be further copied/distributed or hosted elsewhere without the express permission from Taylor \& Francis. 
measure. The correlation between spelling tests was $0.72(p<0.001)$. The linear difference model was not significant $\left(R^{2}=0.02\right)$.

The cusp for arithmetic test scores was more interesting. The overall $R^{2}$ was 0.39 , which was greater than that obtained for the linear pre-post model. The only significant weights in the cusp model, however, were the cubic and quadratic terms; bifurcation and asymmetry variables were not found. The only significant weight in the linear pre-post model was the pre-test arithmetic measure. The correlation between arithmetic tests was $0.48(p<0.001)$. The linear difference model was not significant $\left(R^{2}=0.17\right)$.

\section{Discussion}

This study started with several conflated problems in cognitive workload and fatigue. The first was the relative nature of measurements for cognitive workload, which suggested that a deeper theoretical understanding of the issues was needed to develop a measurement or work load assessment tool that was generalisable to a broad range of situations.

The other problems were theoretical in nature: the upper limits of channel capacity are sometimes fixed and sometimes variable. Some forms of workload involve task variety, whereas others involve task density or time pressure. Some concepts of elasticity, resilience, coping or adaptive capability have come to the foreground and need to be integrated into the big picture. The nature of workload stress and fatigue are often entangled.

The suggested remedy here took the form of two cusp catastrophe models, one that explains buckling stress and workload effects and one that explains fatigue. The model for buckling stress focuses on acute workload demands. The model for fatigue characterises the effects of longer term engagement. Importantly, different features of the workload are critical to the two models. Buckling stress involves different amounts of workload demand as the asymmetry parameter with elasticity-related variables as the bifurcation parameter. Fatigue is the loss of work capacity where the total amount of work accomplished in a time period constitutes the 
bifurcation parameter and a compensatory ability constitutes the asymmetry parameter.

Both models permit improvements in performance as well as declines; whereas a work commitment could produce fatigue in most people, some people could display a rebound effect as if they were 'just getting warmed up.' In the buckling mode, increasing the workload has the effect of bringing people to a critical point where the more elasticity versus rigidity, howsoever it might be ultimately defined psychologically, makes the difference between a sharp shift in performance versus a gradual improvement in the sense of producing greater output in the same amount of time.

The two models were initially predicated on physically intensive work and generalised here to cognitive tasks. There is some precedent for doing so that dates back to the Yerkes-Dodson law that connects arousal with performance, and the earliest fatigue studies that reported similarly shaped work curves for physical and cognitive tasks. Contemporary thinking emphasises embodied cognition, by which cognition and action are combined sequences of behavioural events. It then becomes a matter of degree as to which tasks are more demanding in the physical or cognitive components.

The catastrophe models go a long distance towards explaining conditions where fixed and variable upper limits could occur in the case of workload analysis, explaining the role of constructs related to elasticity, and capturing the full range of work curves associated with fatigue. The concept of degrees of freedom goes further to explain how the underlying mental and physical operations self-organise and change configuration when demand conditions reach a critical point. In doing so it explains how discontinuities are likely to be fundamental to the phenomena. Catastrophe theory explains discontinuities as the result of underlying nonlinear surfaces with two underlying control parameters (in the relatively simple cusp model).

\subsection{Experimental results}

The experiment in this study was designed around basic task conditions. The main work session was occupied by a single task that was intensive in its demand on episodic, digit span memory and attention to details. It was also reliant on both visual and auditory

Theoretical Issues in Ergonomic Science, Vol 13, No. 5 (2012): pg. 586-602. DOI. This article is (C) Taylor \& Francis and permission has been granted for this version to appear in e-Publications@ Marquette. Taylor \& Francis does not grant permission for this article to be further copied/distributed or hosted elsewhere without the express permission from Taylor \& Francis. 
cues. The level of stress was self-induced by the participant. The programme automatically increased speed demand with the load demand, and the individual could attempt higher demand levels or not.

The analysis of buckling stress produced the cusp catastrophe effect as intended, with the maximum performance level, which simultaneously indicated the level of stress demand, as the asymmetry parameter, also as expected. Anxiety was tested as a bifurcation variable, but it did not work out as planned, even though it seemed to work as an elasticity variable in other applications such as the analysis of occupational accidents (Guastello 2003, Guastello and Lynn 2010). It is possible that anxiety is more germane to work environments that are more complex overall, more threatening, and where the exposure is longer term. A social component might also be important, which was minimal in this experiment. The strength of the cusp model for work load, as evidenced thus far, derives from the strength of the cubic term. The strong cubic element in turn indicates that a bifurcation variable must be present; future research needs to find it.

The fatigue cusp worked as planned for the performance on the central task. The bifurcation effect was the amount of work done; if a person did not do much work there would not be much chance of fatigue. Arithmetic ability acted as the compensatory ability. Its relationship to performance change was curious and warrants further investigation. However, one could indulge a post hoc explanation for what could be occurring: a well-known suppressor effect among mental abilities is the negative role of verbal ability in the performance of military pilots, which is primarily a spatially intensive task. The relationship also shows up in cusp catastrophe models for the performance of air force personnel that were designed around personnel selection decisions (Guastello 2002).

The results also showed some spillover from the main task to spelling (or proofreading) and arithmetic performance. The effect on spelling was not catastrophic, and the net effect was a positive shift in performance. This result also warrants further investigation. A post hoc speculation is that the memory task heightened the individual's attention to visual details, which was the aspect of the MySimon game that actually carried over.

Theoretical Issues in Ergonomic Science, Vol 13, No. 5 (2012): pg. 586-602. DOI. This article is (C) Taylor \& Francis and permission has been granted for this version to appear in e-Publications@Marquette. Taylor \& Francis does not grant permission for this article to be further copied/distributed or hosted elsewhere without the express permission from Taylor \& Francis. 
The effect on arithmetic performance was catastrophic in structure, but the control variables were not identified. Fatigue and anti-fatigue effects were unrelated to the total amount of work accomplished on MySimon. This result also warrants further investigation and explanation. Improving the reliability of the arithmetic test would be the first place to start as the parallel form reliability was unexpectedly low.

\subsection{Future research}

A glaring limitation of this study was that the experiment did not extend to the full range of problem situations that the theory portends to address. Future research directions should extend to a wider range of tasks, the use of multiple task designs, tasks that vary by load and speed demand in different ways, and tasks of longer duration as would be encountered in real-world situations. The research programme should include tasks that place demands on a wider range of mental and physical resources. Ultimately, it should be possible to build a network of mental abilities that explains the patterns by which some capabilities are affected by different work demands or facilitate performance on a task even if the particular ability is not the central ability or resource for the task.

Elasticity, coping, or resilience variables should be explored further. The current results for anxiety indicate that some such variables could be highly relevant to some task conditions but not others. There are obviously a lot of unknowns with regard to task structure and elasticity that need to be pieced together in a coherent fashion. Achievement motivation, other sources of arousal or selfefficacy could also be candidate variables. Alternatively, coping schemata might not engage unless the arousal level was sufficiently high.

Degrees of freedom were considered as an important part of the explanation of fatigue and buckling phenomena, but were not explicitly counted in the tasks that were included in the experiment. Another avenue of research should be directed towards doing so, again in a wide variety of task and demand situations.

This research has not yet produced a silver bullet for cognitive workload measurement, which appears to be in high demand. The 
reconceptualisation of workload and fatigue as related but different catastrophe models, however, appears to be an important step towards doing so.

\section{References}

1. Abbott, A. 2005. Unnatural selection: talent identification and development in sport. Nonlinear Dynamics, Psychology, and Life Sciences, 9: 61-88.

2. Ash, IE. 1914. Fatigue and its effects upon control. Archives of Psychology, 31: $1-61$.

3. Bernstein, N. 1967. The coordination and regulation of movements, Oxford: Pergamon.

4. Bills, AG. 1931. Blocking: a new principle of mental fatigue. American Journal of Psychology, 43: 230-245.

5. Chatterji, GB and Sridhar, B. 2001. Measures for air traffic controller workload prediction. Paper presented to the 1st AIAA Aircraft Technology and Operations Forum. 2001. October 2001. Los Angeles, CA: American Institute of Aeronautics \& Astronautics

6. Conrad, R. 1951. Speed and load stress in a psychomotor skill. British Journal of Industrial Medicine, 8: 1-7.

7. Cox-Fuenzalida, L-E. 2007. Effect of workload history on task performance. Human Factors, 49: 277-291.

8. Eberts, R and Salvendy, G. 1986. The contribution of cognitive engineering to the safe design and operation of CAM and robotics. Journal of Occupational Accidents, 8: 49-67.

9. Ein-Dor, T. 2010. The attachment paradox: how can so many of us (the insecure ones) have no adaptive advantages. Perspectives on Psychological Science, 5: 123-141.

10. Gibson, JJ. 1979. The ecological approach to visual perception, Boston: Houghton-Mifflin.

11. Gilmore, R. 1981. Catastrophe theory for scientists and engineers, New York: Wiley.

12. Guastello, SJ. 1985. Euler buckling in a wheelbarrow obstacle course: a catastrophe with complex lag. Behavioral Science, 30: 204-212.

13. Guastello, S]. 1995. Chaos, catastrophe, and human affairs: applications of nonlinear dynamics to work, organizations, and social evolution, Mahwah, NJ: Lawrence Erlbaum.

14. Guastello, SJ. 2002. Managing emergent phenomena: nonlinear dynamics in work organizations, Mahwah, NJ: Lawrence Erlbaum Associates.

15. Guastello, SJ. 2003. Nonlinear dynamics, complex systems, and occupational accidents. Human Factors in Manufacturing, 13: 293304.

Theoretical Issues in Ergonomic Science, Vol 13, No. 5 (2012): pg. 586-602. DOI. This article is (C) Taylor \& Francis and permission has been granted for this version to appear in e-Publications@Marquette. Taylor \& Francis does not grant permission for this article to be further copied/distributed or hosted elsewhere without the express permission from Taylor \& Francis. 
16. Guastello, SJ. 2005. Statistical distributions and self-organizing phenomena: what conclusions should be drawn?. Nonlinear Dynamics, Psychology, and Life Sciences, 9: 463-478.

17. Guastello, SJ. 2006. Human factors engineering and ergonomics: a systems approach, Mahwah, NJ: Lawrence Erlbaum Associates.

18. Guastello, SJ. 2011. "Discontinuities: SETAR and catastrophe models with polynomial regression". In Nonlinear dynamical systems analysis for the behavioral sciences using real data, Edited by: Guastello, SJ and Gregson, RAM. 251-280. Boca Raton, FL: CRC Press/Taylor \& Francis.

19. Guastello, SJ and Johnson, EA. 1999. The effect of downsizing on hierarchical work flow dynamics. Nonlinear Dynamics, Psychology, and Life Sciences, 3: 352-379.

20. Guastello, SJ and Lynn, M. 2010. Catastrophe model of the accident process, safety climate, and anxiety. Paper presented to the 4th international nonlinear science conference. March 20102010, Palermo. Italy

21. Guastello, SJ and McGee, DW. 1987. Mathematical modeling of fatigue in physically demanding jobs. Journal of Mathematical Psychology, 31: 248-269.

22. Haken, H. 1988. Information and self-organization: a macroscopic approach to self-organization, New York: Springer-Verlag.

23. Hancock, PA and Desmond, PA. 2001. Stress, workload, and fatigue. Mahwah, NJ: Lawrence Erlbaum Associates

24. Hancock, PA and Warm, JS. 1989. A dynamic model of stress and sustained attention. Human Factors, 31: 519-537.

25. Harris, WC, Hancock, PA and Harris, SC. 2005. Information processing changes following stress. Military Psychology, 17: 115-128.

26. Hendy, KC, Liao, JQ and Milgram, P. 1997. Combining time and intensity in assessing operator information load. Human Factors, 39: 30-47.

27. Hockey, GRJ. 1997. Compensatory control in the regulation of human performance under stress and high workload: a cognitive-energetical framework. Biological Psychology, 45: 73-93.

28. Hollis, G, Kloos, H and Van Orden, GC. 2009. "Origins of order in cognitive activity". In Chaos and complexity in psychology: the theory of nonlinear dynamical systems, Edited by: Guastello, SJ, Koopmans, $M$ and Pincus, D. 206-242. New York: Cambridge University Press.

29. Hong, SL. 2010. The entropy conservation principle: applications in ergonomics and human factors. Nonlinear Dynamics, Psychology, and Life Sciences, 14: 291-315.

30. Hristovski, R, Davids, K and Aradjo, D. 2006. Affordance-controlled bifurcations of action patterns in martial arts. Nonlinear Dynamics, Psychology, and Life Sciences, 10: 409-444.

31. Ioteyko, J. 1920. La fatigue [Fatigue], , 2nd, Paris: Flammarion.

Theoretical Issues in Ergonomic Science, Vol 13, No. 5 (2012): pg. 586-602. DOI. This article is (C) Taylor \& Francis and permission has been granted for this version to appear in e-Publications@Marquette. Taylor \& Francis does not grant permission for this article to be further copied/distributed or hosted elsewhere without the express permission from Taylor \& Francis. 
32. Kantowitz, BH. 1985. Channels and stages in human information processing: a limited analysis of theory and methodology. Journal of Mathematical Psychology, 29: 135-174.

33. Lin, $\mathrm{Y}$ and Cai, H. 2009. A method for building a real-time cluster-based continuous mental workload scale. Theoretical Issues in Ergonomic Science, 10: 531-544.

34. Loft, S. 2007. Modeling and predicting mental workload in en route air traffic control: critical review and broader implications. Human Factors, 49: 376-399.

35. Marken, RS. 1991. Degrees of freedom in behavior. Psychological Science, 2: 86-91.

36. Matthews, G and Campbell, SE. 2009. Sustained performance under overload: personality and individual differences in stress and coping. Theoretical Issues in Ergonomics Science, 10: 417-443.

37. Mayer-Kress, G, Newell, KM and Liu, Y-T. 2009. Nonlinear dynamics of motor learning. Nonlinear Dynamics, Psychology, and Life Sciences, 13: 3-26.

38. Morineau, T. 2009. Turing machine as an ecological model for task analysis. Theoretical Issues in Ergonomics Science, 10: 511-530.

39. Software, NCH. 2009. Debut video capture software [online]. Retrieved 1 October 2009. Available from: http://www.nchsoftware.com/capture/index.html [Accessed 21 January 2011]

40. Neave, P. 2009. MySimon [online]. Retrieved 1 October 2009. Available from: http://www.freegames.ws/games/kidsgames/simon/mysimon.htm [Accessed 21 January 2011]

41. Neerincx, MA and Griffioen, E. 1996. Cognitive task analysis: harmonizing tasks to human capabilities. Ergonomics, 39: 543-561.

42. Pincus, $D$ and Metton, A. 2010. Nonlinear dynamics in biopsychosocial resilience. Nonlinear Dynamics, Psychology, and Life Sciences, 14: 353-380.

43. Renaud, P, Chartier, $S$ and Albert, G. 2009. "Embodied and embedded: the dynamics of extracting perceptual visual invariants". In Chaos and complexity in psychology: the theory of nonlinear dynamical systems, Edited by: Guastello, SJ, Koopmans, M and Pincus, D. 177-205. New York: Cambridge University Press.

44. Rosenbaum, DA. 1991. Optimal movement selection. Psycholoical Science, 2: 92-101.

45. Selye, H. 1976. The stress of life, , 2nd, New York: McGraw-Hill.

46. Sheridan, TB. 2008. Risk, human error, and system resilience: fundamental ideas. Human Factors, 50: 418-426.

Theoretical Issues in Ergonomic Science, Vol 13, No. 5 (2012): pg. 586-602. DOI. This article is (C) Taylor \& Francis and permission has been granted for this version to appear in e-Publications@Marquette. Taylor \& Francis does not grant permission for this article to be further copied/distributed or hosted elsewhere without the express permission from Taylor \& Francis. 
NOT THE PUBLISHED VERSION; this is the author's final, peer-reviewed manuscript. The published version may be accessed by following the link in the citation at the bottom of the page.

47. Townsend, JT and Wenger, MJ. 2004. A theory of interactive parallel processing: new capacity measures and predictions for a response time inequality series. Psychological Review, 30: 708-719.

48. Turvey, MT. 1990. Coordination. American Psychologist, 45: 938-953.

49. Wickens, CD. 2008. Multiple resources and mental workload. Human Factors, 50: 449-455.

50. Zeeman, EC. 1977. Catastrophe theory: selected papers 1972-1977, Reading, MA: Addison-Wesley.

Theoretical Issues in Ergonomic Science, Vol 13, No. 5 (2012): pg. 586-602. DOI. This article is (C) Taylor \& Francis and permission has been granted for this version to appear in e-Publications@Marquette. Taylor \& Francis does not grant permission for this article to be further copied/distributed or hosted elsewhere without the express permission from Taylor \& Francis. 